\title{
Dissemination of antibiotic resistance genes and their potential removal by on-farm treatment processes in nine swine feedlots in Shandong Province, China
}

\author{
Weiwei Ben ${ }^{\mathrm{a}}$, Jian Wang ${ }^{\mathrm{b}, \mathrm{c}}$, Xun Pan ${ }^{\mathrm{d}}$, Zhimin Qiang ${ }^{\mathrm{a}, *}$ \\ ${ }^{a}$ Key Laboratory of Drinking Water Science and Technology, Research Center for Eco-Environmental Sciences, University of Chinese Academy of Sciences, \\ Chinese Academy of Sciences, 18 Shuang-qing Road, Beijing 100085, China \\ b Institute of Energy and Environmental Protection, Chinese Academy of Agricultural Engineering, 41 Maizidian Street, Beijing 100125, China \\ ${ }^{\mathrm{c}}$ Key Laboratory of Energy Resource Utilization from Agricultural Residues, Ministry of Agriculture, 41 Maizidian Street, Beijing 100125, China \\ ${ }^{\mathrm{d}}$ Foreign Economic Cooperation Office, Ministry of Environmental Protection, Beijing 100035, China
}

\section{H I G H L I G H T S}

- RPP TRGs were dominant in swine wastes but tended to decrease in treatment processes.

- EFP TRGs and SRGs were recalcitrant to treatments and persistent in environment.

- MFB showed "broad-spectrum" removal for tested ARGs.

- Proteobacteria were found to be important host phyla harboring ARGs.

- Most on-farm treatment processes failed to eliminate ARGs.

\section{A R T I C L E I N F O}

\section{Article history:}

Received 30 July 2016

Received in revised form

2 October 2016

Accepted 3 October 2016

Available online 8 October 2016

Handling Editor: Shane Snyder

\section{Keywords:}

Antibiotic resistance genes

Dissemination

Removal

On-farm treatment process

Swine feedlot
G R A P H I C A L A B S T R A C T

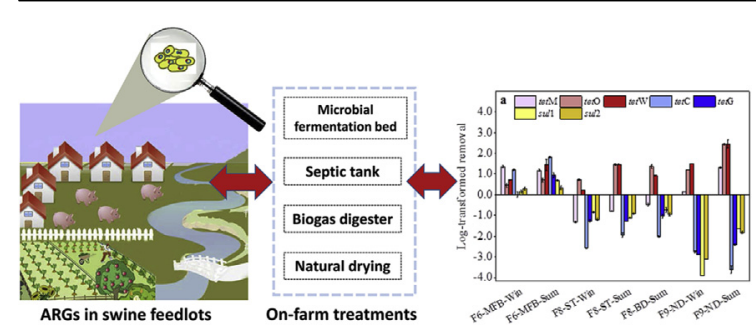




\section{Introduction}

Antibiotic resistance genes (ARGs), as a class of emerging contaminants (Pruden et al., 2006), have drawn considerable attention due to their threat of hampering clinical therapies for bacterial infections. The wide application of antibiotics in concentrated swine feedlots for growth promotion and disease treatment has induced the evolution and subsequent spread of antibiotic resistance. As a result, ARGs encoding resistance to several commonlyused classes of antibiotics were found prevalent in wastewater and manure from swine feedlots worldwide (Koike et al., 2007; Mckinney et al., 2010; Negreanu et al., 2012; Peng et al., 2015).

China is the largest antibiotic-consuming country in the world, and it is estimated that more than half of the usage $\left(8.4 \times 10^{4}\right.$ tons $)$ was applied in the livestock and poultry industry in 2013 (Zhang et al., 2015). China produces a large amount of swine wastes every year, which may harbor ARGs of elevated levels (Cheng et al., 2013; Zhu et al., 2013). Moreover, because of the inefficient management of swine wastes, adjacent environments were vulnerable to contamination by ARGs through discharge of swine wastewater and farmland application of swine manure compost (Ji et al., 2012; Li et al., 2012; Wu et al., 2010). Our previous study has revealed that tetracycline resistance genes (TRGs) and sulfonamide resistance genes (SRGs) in a typical concentrated swine feedlot located in Beijing could readily disseminate along the swine waste treatment paths, and thus were detected with considerable abundances in nearby soils and a receiving river (Wang et al., 2016). However, to date, the information regarding the types and concentrations of ARGs disseminated from swine feedlots in China is still very limited, particularly that at a regional scale.

In response to the increasing risks induced by the dissemination of ARGs originating from swine feedlots, on-farm waste treatment processes need to be assessed with respect to their treatment efficiencies for ARGs. It was found that anaerobic lagoons, which are widely applied to store swine wastes flushed out of swine houses, could not effectively eliminate ARGs (Chen et al., 2010; Mckinney et al., 2010). Other biological treatment processes, such as microbial fermentation bed (MFB) (Wang and Guo, 2009), septic tank (ST) and biogas digester (BD) (Jiang et al., 2011), have also been operated in swine feedlots in China, but their treatment efficiencies for ARGs still remain largely unknown.

Therefore, the present study was to determine the dissemination of ARGs from swine feedlots to adjacent environments at a regional scale and examine the performance of representative onfarm waste treatment processes currently in use for eliminating ARGs. The abundances of five TRGs and two SRGs were measured by the quantitative polymerase chain reaction (q-PCR) method in swine wastewater and manure from nine concentrated swine feedlots as well as in nearby soils and wastewater-receiving river sediments in Shandong Province, China. The elimination of target ARGs by four waste treatment processes was also tested, and bacterial community was analyzed by pyrosequencing to explore the removal mechanisms of ARGs.

\section{Material and methods}

\subsection{Swine feedlots and sample collection}

Shandong Province was selected as the region of interest because of its large quantity of corralled pigs and high consumption of veterinary antibiotics. Samples were collected from nine concentrated swine feedlots located in Jinan and Dezhou cities of Shandong Province. Detailed information on the breeding scales, waste treatment processes, and sample collection of the studied feedlots is shown in Table 1.
Specifically, samples were collected depending on the operation modes of the studied feedlots. Manure samples included piglet manure (PM), sow manure (SM), and fattening pig manure (FM). Fertilized soil (FS) samples were taken from farmlands fertilized with composted manure; and unfertilized soil (US) samples were taken from farmlands adjacent to the feedlots but without manure fertilization. House wastewater (HW) samples were directly collected from drainage channels inside the swine houses, which mainly consisted of swine urine, a certain fraction of manure and house washing water. If the wastewater was directly discharged to an outdoor channel, discharged wastewater (DW) samples were collected at the end of the channel. The DW of five studied feedlots finally flowed into adjacent rivers, so river sediment (RS) samples were collected at about $50 \mathrm{~m}$ away from the discharge outlet. Among the nine swine feedlots, F6 and F8 employed MFB, ST, or BD (only operated in summer) process to treat swine wastes; F9 adopted a static natural drying (ND) method to simply solidify the manure; whilst all other feedlots did not use any waste treatment process. Treated wastes were collected from the relevant treatment facilities. In total, 53 summer samples (August 2014) and 52 winter samples (January 2015) were collected. For each sample, four subsamples were collected and then mixed into one composite sample. All samples were stored in ice-packed coolers and transported immediately to the laboratory for subsequent analysis.

\subsection{DNA extraction and quantification of ARGs}

All DNA extractions were performed using the FastDNA SPIN kit for soil (MP-bio, USA). For solid samples, each fresh sample of $0.2 \mathrm{~g}$ was used; for wastewater samples, each fresh sample of $10 \mathrm{~mL}$ was filtered through $0.22-\mu \mathrm{m}$ polyvinylidene fluoride membranes (Millipore, USA), and then the membranes were cut into pieces with pre-sterilized scissors and subjected to DNA extraction. The DNA extraction and subsequent ARG quantifications for each sample were carried out in triplicate.

Three TRGs encoding ribosomal protection proteins (RPP) (tetM, tetO, and tet $\mathrm{W}$ ) and two TRGs encoding efflux pump proteins (EFP) (tetC and tetG), as well as two SRGs encoding mutant dihydropteroate synthase genes (sul1 and sul2), were quantified using the q-PCR method according to our former study (Wang et al., 2015). To avoid large fluctuations in the absolute ARG abundances, which could be severely impacted by the total biomass in each DNA extraction, the relative ARG abundance (ARG per 16S rRNA gene) was used in this study.

\subsection{Bacterial community analysis using pyrosequencing}

To evaluate the variations of bacterial communities in treated wastes, the variable V3 and V4 regions of the bacterial 16S rRNA gene in related samples (F6-MFB, F8-ST, F8-BD and F9-ND) were amplified using the primer pair 341F $\left(5^{\prime}\right.$-CCTAYGGGRBGCASCAG$\left.3^{\prime}\right)$ and 806R (5'-GGACTACHVGGGTWTCTAAT- $3^{\prime}$ ) (Michelsen et al., 2014). The PCR mixture ( $30 \mu \mathrm{L})$ consisted of $15 \mu \mathrm{L}$ of Phusion HighFidelity PCR Master Mix (NEB, USA), $0.2 \mu \mathrm{M}$ forward and reverse primers, and 5-10 ng of template DNA. PCR was run with the following program: initial denaturation at $98^{\circ} \mathrm{C}$ for $1 \mathrm{~min}$, followed by 30 cycles of denaturation for $10 \mathrm{~s}$ at $98^{\circ} \mathrm{C}$, annealing for $30 \mathrm{~s}$ at $50{ }^{\circ} \mathrm{C}$ and extension for $30 \mathrm{~s}$ at $72{ }^{\circ} \mathrm{C}$, and finished with a final extension at $72{ }^{\circ} \mathrm{C}$ for $5 \mathrm{~min}$. PCR products were checked by electrophoresis in agarose gel (2\%), and samples with a bright main strip between 400 and 450 bp were qualified for further analysis. After the PCR products were purified with the Gene JET Gel Extraction Kit (Thermo Scientific, USA), sequencing libraries were generated using an NEB Next Ultra DNA Library Prep Kit from Illumina (NEB, USA) following the manufacturer's instructions. 
Table 1

Detailed information about the nine swine feedlots in Shandong Province, China.

\begin{tabular}{|c|c|c|c|c|c|c|c|c|c|c|c|c|c|c|}
\hline \multirow[t]{2}{*}{ Feedlot no. } & \multirow[t]{2}{*}{ Piglet } & \multirow[t]{2}{*}{ Sow } & \multirow[t]{2}{*}{ Fattening pig } & \multicolumn{2}{|c|}{ Treatment process } & \multicolumn{9}{|c|}{ Sample ${ }^{\mathrm{a}}$} \\
\hline & & & & Wastewater & Manure & PM & SM & FM & FS & US & HW & DW & RS & TW \\
\hline \multicolumn{15}{|l|}{ Jinan City } \\
\hline $\mathrm{F} 1$ & 0 & 0 & 1200 & No treatment & & & & - & & $\bullet$ & $\bullet$ & $\bullet$ & & \\
\hline $\mathrm{F} 2$ & 1400 & 240 & 0 & No treatment & & 0 & 0 & & & & 0 & $\bullet$ & 0 & \\
\hline F3 & 150 & 700 & 700 & No treatment & & 0 & 0 & $\bullet$ & $\bullet$ & $\bullet$ & 0 & $\bullet$ & 0 & \\
\hline F4 & 800 & 400 & 800 & No treatment & & 0 & 0 & 0 & - & 0 & 0 & & & \\
\hline F5 & 0 & 0 & 200 & No treatment & & & & 0 & & 0 & 0 & $\bullet$ & $\bullet$ & \\
\hline \multicolumn{15}{|c|}{ Dezhou City } \\
\hline F6 & 300 & 200 & 1000 & Microbial ferm & ation bed & $\bullet$ & $\bullet$ & $\bullet$ & & & & & $\bullet$ & $\bullet$ \\
\hline F7 & 300 & 300 & 100 & No treatment & & 0 & 0 & 0 & $\bullet$ & & $\bullet$ & $\bullet$ & 0 & \\
\hline F8 & 300 & 100 & 600 & Septic tank or & gas digester & $\bullet$ & 0 & 0 & - & & & & & 0 \\
\hline F9 & 2000 & 500 & 3000 & No treatment & Natural drying & 0 & 0 & 0 & 0 & & $\bullet$ & - & & 0 \\
\hline
\end{tabular}

${ }^{a}$ PM, piglet manure; SM, sow manure; FM, fattening pig manure; FS, fertilized soil; US, unfertilized soil; HW, swine house wastewater; DW, discharged wastewater; RS, river sediment; TW, treated wastes.

Library quality was assessed using a Qubit2.0 Fluorometer (Thermo Scientific, USA) and Bioanalyzer 2100 system (Agilent Technologies, USA). Afterward, the library was sequenced using an Illumina HiSeq platform, and 250 bp paired-end reads were generated. Sequencing data analyses were accessed following a previous study (Liu et al., 2016).

\subsection{Statistical analysis}

All experimental data were analyzed statistically by SPSS 19.0 (IBM, USA). The paired samples $t$-test based on $p$-values (significant threshold $=0.05$ ) was used to evaluate the significance of difference among samples. The correlations between ARGs and bacterial species were evaluated by Pearson's bivariate correlation analysis. Principal components analysis (PCA) was used to cluster the soil and RS samples with Canoco 4.5 for Windows.

\section{Results and discussion}

\subsection{ARGs in swine manure and soils}

The distributions of studied ARGs in swine manure and adjacent soil samples are shown in Fig. 1, with their detailed relative abundances available in Table S1 (Supplementary Data).

In the manure samples (PM, SM, and FM), RPP TRGs (tetM, tetO, and tetW) were the dominant ARG types, with mean relative abundances at $10^{-3}-10^{-1}$ levels. tetO showed the highest relative abundance, with mean values of $8.9 \times 10^{-2}$ (PM in summer)$5.2 \times 10^{-1}$ (FM in summer), followed by tetW and tetM with mean values of $4.2 \times 10^{-2}$ (PM in summer) $-1.6 \times 10^{-1}$ (FM in winter) and $3.2 \times 10^{-3}$ (SM in winter) $-2.0 \times 10^{-2}$ (FM in summer), respectively. SRGs were also detected with high relative abundances, and the mean values were in the ranges of $8.5 \times 10^{-3}$ (SM in summer)$2.1 \times 10^{-2}$ (FM in summer) and $5.6 \times 10^{-3}$ (FM in summer)$3.1 \times 10^{-2}$ (PM in winter) for sul1 and sul2, respectively. Relatively low levels of EFP TRGs were detected, only showing mean values of $3.3 \times 10^{-5}$ (SM in summer)-2.9 $\times 10^{-3}$ (FM in winter) and $4.1 \times 10^{-4}(\mathrm{FM}$ in winter $)-5.9 \times 10^{-3}$ (SM in winter) for tetC and tet $\mathrm{G}$, respectively. With regard to the manure of different pig types, no significant difference in the ARG levels between summer and winter was observed $(p>0.05)$. The maximal levels of TRGs and SRGs were detected in FM and PM, respectively. This result coincides with the distributions of TRGs and SRGs in different types of manure from a swine feedlot in Beijing (Wang et al., 2016), and can mainly be attributed to the different antibiotic dose levels for different pig types depending on the varied demands for growth promotion and disease prevention. In swine farms located in the

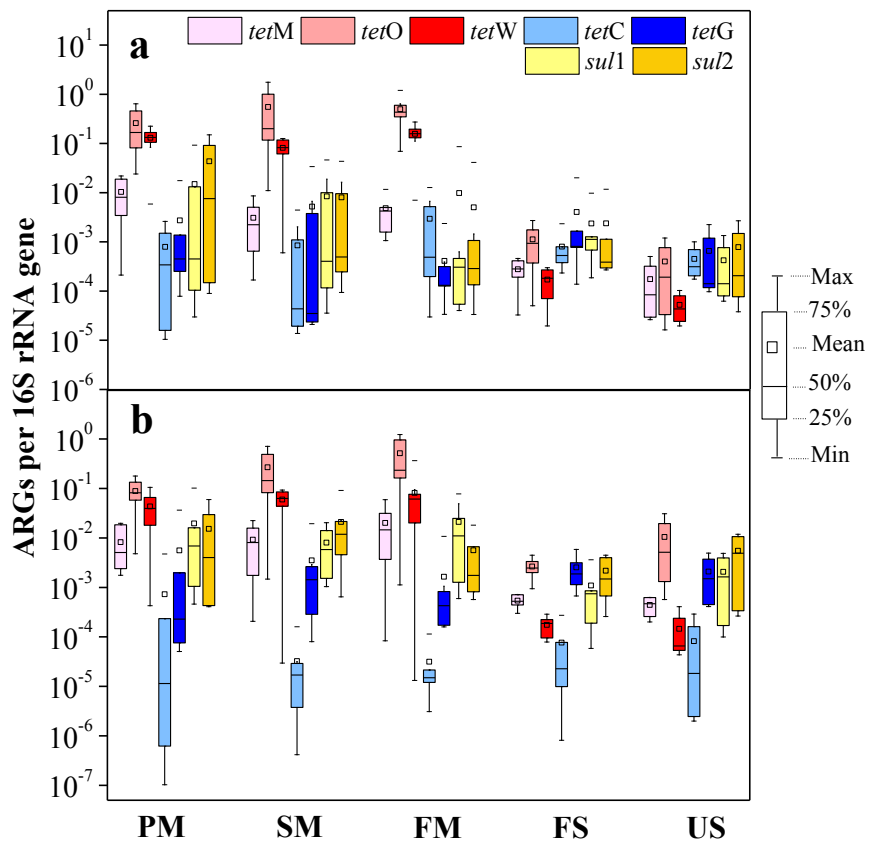

Fig. 1. Relative abundances of antibiotic resistance genes (ARGs) along manure treatment paths from nine swine feedlots in winter (a) and summer (b). Sample symbols: piglet manure (PM), sow manure (SM), fattening pig manure (FM), manure-fertilized soil (FS), and unfertilized soil (US).

United States, Brooks et al. (2014) found that fattening pig farms harbored fewer ARGs than sow and piglet farms. Hence, the distribution of ARG levels in excretion from various pig types may differ from different areas.

In the soil samples (FS and US), a significant decrease in the relative abundances of RPP TRGs was observed, while those of EFP TRGs and SRGs only decreased by a small degree. As a result, the levels of different ARGs became closer in the soil samples, which ranged from $9.9 \times 10^{-5}$ (tetW in US) to $1.1 \times 10^{-2}$ (tetO in US). This result is consistent with those of former studies, that is, RPP TRGs were dominant in swine manure but declined markedly in downstream soils (Wang et al., 2016; Zhu et al., 2013). The instability of RPP TRGs was probably attributed to a considerable decrease of antibiotic selection pressure in the soils and inactivation of enteric bacteria harboring RPP TRGs after manure composting and fertilization (Aminov et al., 2001). EFP TRGs and SRGs were more stable than RPP TRGs, which was probably attributed to their strong mobility, as they are often associated with mobile genetic elements, 
such as plasmids and integrons (Boyd et al., 2000; Mazel, 2006; Roberts, 2012; Smalla et al., 2000). In winter, slightly higher levels of all the tested ARGs were observed in FS than in US (Fig. 1a), indicating that the farmland application of composted manure enhanced the resistance levels in the soils. In summer, a slight decrease of ARG levels was observed in FS, while elevated ARG levels were found in US (Fig. 1b). On the one hand, high amounts of rainfall in summer may dilute the ARGs in the FS. On the other hand, the rainfall may cause an unintentional dissemination of ARGs from swine feedlots (e.g., through seepage of storage lagoon wastewater) and fertilized soils to adjacent unfertilized soils.

\subsection{ARGs in swine wastewater and receiving river sediments}

The AGR levels in swine wastewater and wastewater-receiving river sediments are shown in Fig. 2, with their relative abundances detailed in Table S2. In the HW samples, the mean relative abundances of RPP TRGs $\left(9.4 \times 10^{-2}-1.7 \times 10^{-1}\right.$ in winter and $2.1 \times 10^{-2}-5.9 \times 10^{-2}$ in summer) were higher than those of EFP TRGs $\left(7.3 \times 10^{-3}-1.6 \times 10^{-2}\right.$ in winter and $9.8 \times 10^{-3}-1.7 \times 10^{-2}$ in summer), and the predominance of RPP TRGs was particularly distinct in winter. Similar results were observed in the manure samples. A possible reason is that the frequent use of antibiotics for treating diseases in winter led to higher resistance levels in enteric bacteria (Looft et al., 2012). The mean relative abundances of SRGs ranged from $2.0 \times 10^{-2}$ to $4.1 \times 10^{-2}$ in winter and from $3.9 \times 10^{-2}$ to $4.6 \times 10^{-2}$ in summer, which fell in between those of RPP TRGs and EFP TRGs.

In the DW samples, the mean relative abundances of RPP TRGs were $1.1 \times 10^{-2}-1.5 \times 10^{-2}$ in winter and $3.9 \times 10^{-3}-5.7 \times 10^{-3}$ in summer, which were close to those of EFP TRGs $\left(2.1 \times 10^{-3}-1.9 \times 10^{-2}\right.$ in winter and $5.7 \times 10^{-3}-1.5 \times 10^{-2}$ in summer) but exhibited a notable reduction as compared to those in the HW samples. SRGs behaved more stably and thus became the dominant ARG types in the DW, with mean relative abundances of $2.0 \times 10^{-2}-1.9 \times 10^{-2}$ in winter and $1.5 \times 10^{-2}-1.7 \times 10^{-2}$ in summer. In the RS samples, the mean abundances of RPP TRGs, EFP TRGs and SRGs were in the ranges of $1.5 \times 10^{-3}-3.9 \times 10^{-3}$, $1.2 \times 10^{-3}-2.6 \times 10^{-3}$ and $3.0 \times 10^{-3}-7.7 \times 10^{-3}$ in winter and $3.1 \times 10^{-4}-4.0 \times 10^{-3}, 8.6 \times 10^{-4}-1.3 \times 10^{-3}$ and

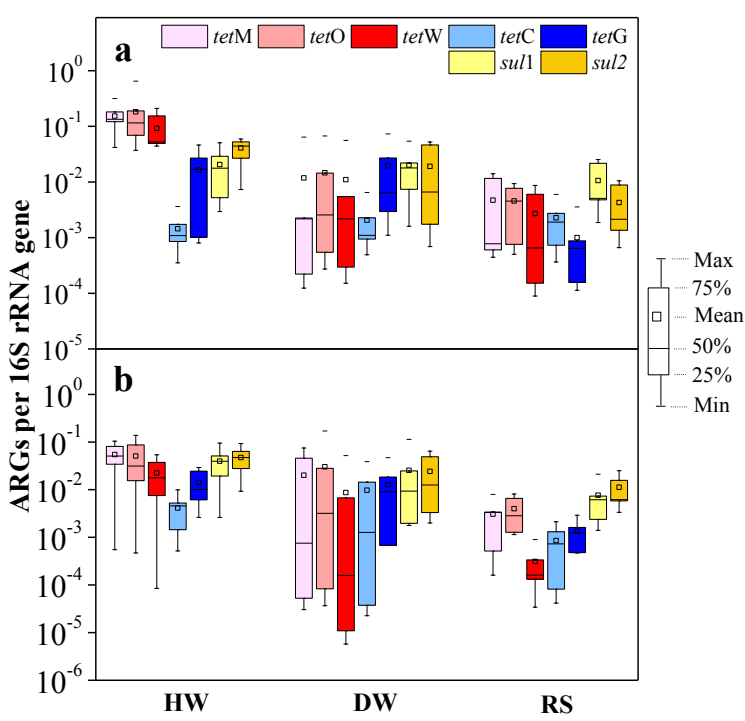

Fig. 2. Relative abundances of ARGs along wastewater discharge paths from nine swine feedlots in winter (a) and summer (b). Sample symbols: house wastewater (HW), discharged wastewater (DW), and river sediment (RS).
$7.7 \times 10^{-3}-1.1 \times 10^{-2}$ in summer, respectively. The similar magnitudes of ARGs in the RS and DW samples in winter denoted a significant influence of the discharged swine wastewater on the ARG levels in receiving waters. In summer, relatively lower TRG levels were observed in the RS than in the DW, while the SRGs remained fairly stable again and became the predominant types in the RS (Fig. 2b). The high mobility of SRGs and the low energy cost for bacteria to carry SRGs (Sköld, 2000) could account for their persistence in swine wastes and natural environment as well.

\subsection{Characteristics of ARGs in soils and wastewater-receiving river sediments}

The dissemination of ARGs from animal feedlots to the surrounding environment has drawn great attention recently ( $\mathrm{He}$ et al., 2016; Li et al., 2012). Manure-fertilized soils and wastewater-receiving river sediments could be important environmental reservoirs of ARGs originating from swine feedlots (Kristiansson et al., 2011; Wu et al., 2010). In this study, PCA was performed to cluster the related samples and analyze the variations in their composition. Fig. 3a shows an obvious seasonal change of ARGs in soils from summer to winter, but only a small change from the FS to US samples. As discussed above, the high rainfall in summer could lead to the dissemination of ARGs from swine feedlots and fertilized soils to adjacent unfertilized soils, thus equalizing the ARG compositions in different soils (Saini et al., 2003). However, Fig. 3b shows an insignificant seasonal change of ARGs in river sediments from summer to winter, but an obvious regional change from Dezhou City (F6 and F7) to Jinan City (F2, F3 and F5). The types and doses of antibiotics applied in swine feedlots had an important impact on the ARG composition in swine wastewater (Peak et al., 2007) and in downstream wastewaterreceiving river sediments. Thus, the different ARG compositions in the RS samples between Dezhou and Jinan cities may reflect the different administration patterns of the two cities.

\subsection{Removal of ARGs in various on-farm treatment processes}

The prevalence of ARGs in swine wastes and their risk of dissemination to adjacent environmental matrices necessitate the assessment of swine waste treatment processes currently in use for removing ARGs. The responses of ARGs to several on-farm treatment processes adopted in the studied swine feedlots are shown in Fig. 4. The log-transformed removal of ARGs was calculated based on their relative abundances in the raw and treated wastes. Results indicate that among the tested processes, MFB had the highest removal efficiency for ARGs, by which the relative ARG abundances were reduced by $0-1.81$ logs (Fig. 4a) and finally reached the levels of $4.3 \times 10^{-6}$ (tetW in summer)-6.1 $\times 10^{-2}$ (sul1 in winter) in the treated wastes (Fig. 4b). MFB was operated by adding fermentative bacterial strains which would compete against the aboriginal bacteria in swine wastes; and meanwhile, the heat production during fermentation could effectively inactivate the aboriginal bacteria. Therefore, the inhibition of aboriginal bacteria harboring ARGs in the MFB was mainly responsible for the effective reduction of ARGs.

All other waste treatment processes (i.e., ST, BD, and ND) exhibited undesirable removal efficiencies for ARGs, but presented different impacts. With respect to RPP TRGs, tetO and tetW were eliminated more easily in all cases (by $0.20-2.40$ logs), and their relative abundances reached the levels of $1.8 \times 10^{-4}$ (tetW in ND in summer) $-1.1 \times 10^{-1}$ (tetO in ST in winter) in the treated wastes. In contrast, tetM was recalcitrant to the ST and BD treatments, whose relative abundances increased by $0.47-1.31$ logs and finally reached the levels of $1.3 \times 10^{-2}$ (in BD in summer) $-8.7 \times 10^{-2}$ (in $\mathrm{ST}$ in winter). The different behavior of tetM could be due to its 

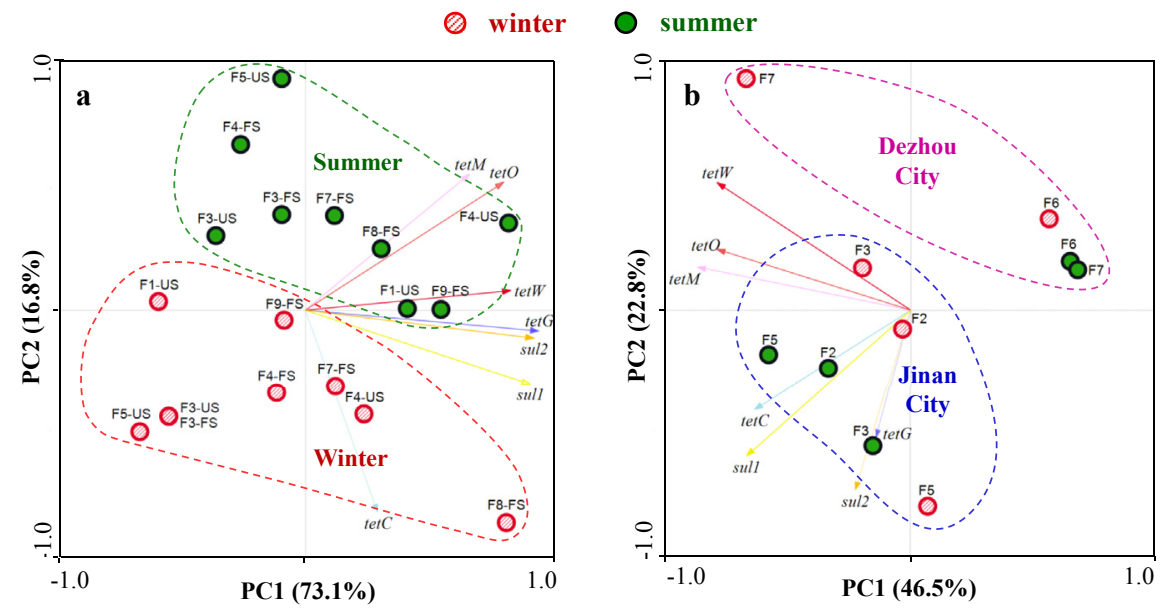

Fig. 3. Principal components analysis of ARGs in soils (a) and river sediments (b). Circles indicate possible sample groups according to their origins.

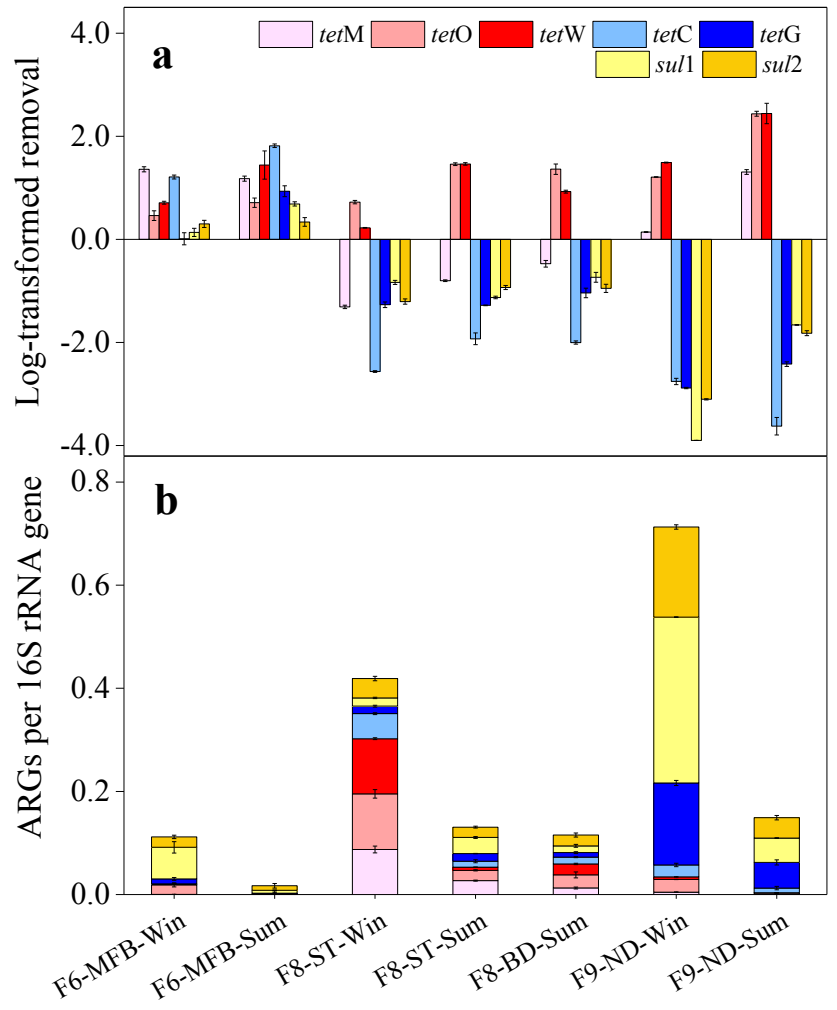

Fig. 4. Removal of ARGs by on-farm treatment processes (a) and relative abundances of ARGs in treated wastes (b). Sample symbols: winter (Win), summer (Sum), microbial fermentation bed (MFB), septic tank (ST), biogas digester (BD), and natural drying (ND).

widest range of host bacteria among the TRGs, which renders its prevalence in the bacterial communities (Roberts, 2012). It is worth noting that the ND always showed a reduction (0.14-2.43 logs) of all RPP TRGs, implying that moisture could be important for their maintenance. The relative abundances of EFP TRGs and SRGs increased after all ST, BD and ND treatments (by 0.74-3.90 logs), and reached the levels of $8.7 \times 10^{-3}$ (tetG in $\mathrm{BD}$ in summer)$3.2 \times 10^{-1}$ (sul1 in ND in winter) in the treated wastes.

In addition, Fig. 4a shows that relatively higher removal efficiencies of tested ARGs were achieved in summer than in winter.
Hence, a high temperature seems to favor the elimination of ARGs. Overall, the ARG levels in the treated wastes in winter were obviously higher than those in summer (Fig. 4b), which could be attributed to both the lower removal efficiencies (Fig. 4a) and higher initial abundances of ARGs (Fig. 1) in this season.

The performance of different treatment processes in removing ARGs in swine wastes has also been assessed by other researchers. In most cases, ARGs could survive the treatment processes, such as mesophilic anaerobic digestion (Chen et al., 2010) and lagoon storage (Mckinney et al., 2010; Pei et al., 2007). A moderate attenuation of TRGs was observed in lagoons, while SRGs were found to be recalcitrant to various treatments. In this study, the MFB could remove both TRGs and SRGs, suggesting its potential for controlling the dissemination of ARGs in swine wastes.

\subsection{Change of bacterial communities in treated wastes and its impact on ARGs}

ARGs can persist in extracellular gene elements, such as plasmids and even naked DNA fragments (Thomas and Nielsen, 2005), but their replications need to proceed intracellularly. Thus, the change in bacterial communities is prone to affect the proliferation and behavior of ARGs.

The bacterial cluster heat map in Fig. 5a shows the top 35 most abundant bacterial genera in treated wastes. The main bacterial genera in the MFB-treated samples (Methylophaga, Streptomyces, Luteimonas, Xylanimicrobium, and Corynebacterium) were distinctly different from those in the samples with other treatments. Meanwhile, the Venn map (Fig. 5b) shows that the number of unique bacterial species in the MFB (593) was much higher than those in other treatments $(104,106,224$, and 242). This result confirms that the evolution of bacterial communities in the MFB played a crucial role in eliminating ARGs. In contrast, the BD, ST and ND processes may not significantly change the bacterial communities in swine wastes, which could make for the horizontal spread of resistance. Hence, these treatment processes served as reservoirs of ARGs instead of eliminating them.

Pearson's bivariate correlation analysis between the relative ARG abundances and bacterial orders was performed to clarify the impact of bacterial communities on the tested ARGs. Among a total of 176 bacterial orders obtained from the pyrosequencing data, 19 orders were significantly correlated with the seven tested ARGs (Table 2), and of which 16 orders were Gram-negative bacteria. This result suggests that Gram-negative bacteria were the main species 


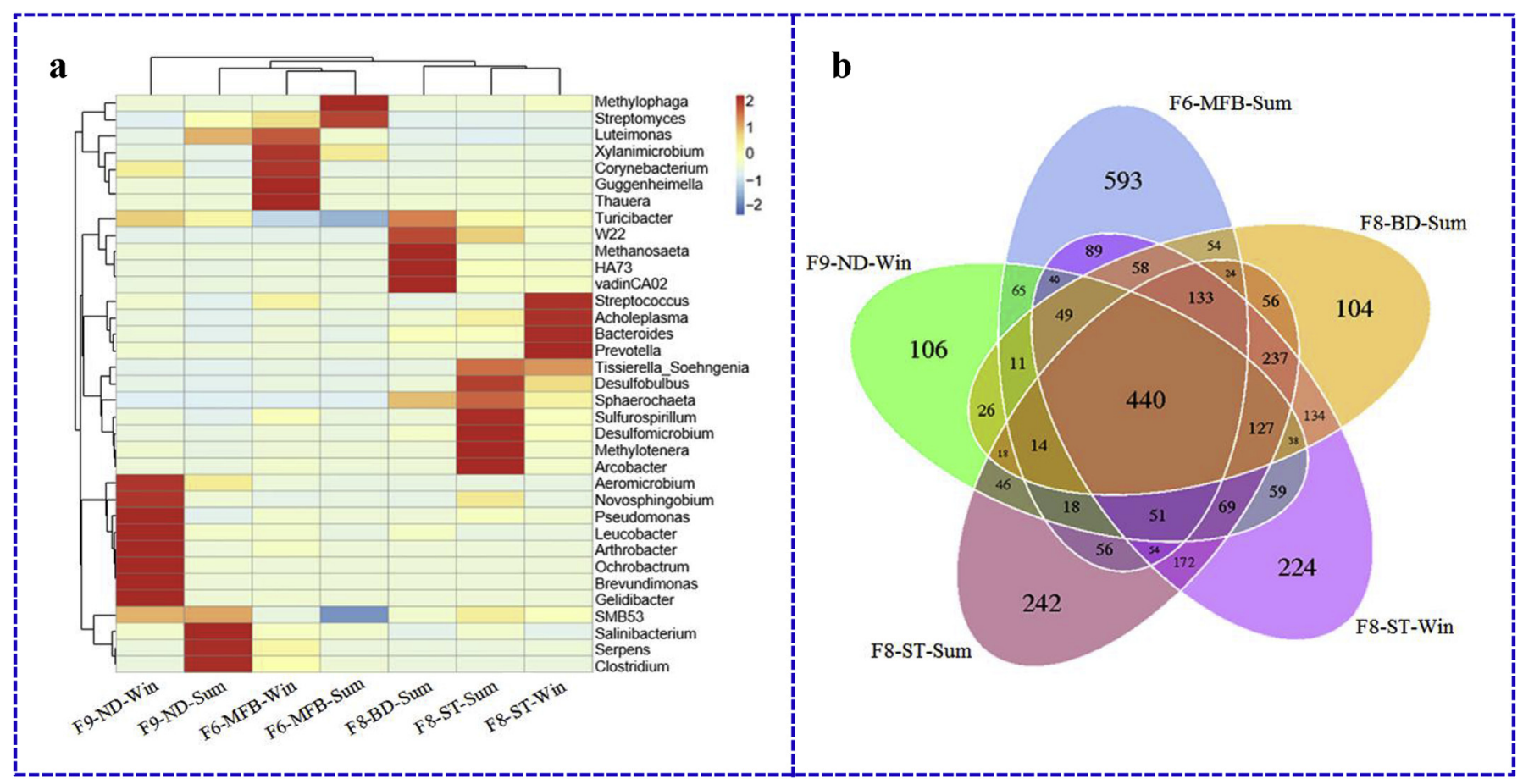

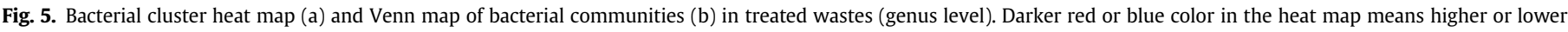

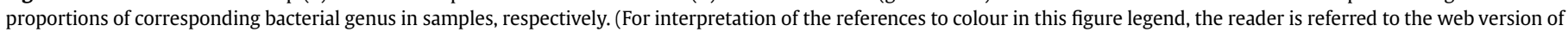
this article.)

affecting the behavior of ARGs in the treatment processes. Moreover, out of the 16 Gram-negative bacterial orders, 7 orders belonged to Alpha- (Rhizobiales and Caulobacterales), Beta- (Burkholderiales, Nitrosomonadales, and Hydrogenophilales) and Gamma- (Alteromonadales and Aeromonadales) Proteobacteria. Similarly, Proteobacteria were found to be dominant in swine manure and manure-fertilized soils (Johnson et al., 2016). Therefore, Proteobacteria are likely to be an important propagation carrier of ARGs and should be paid more attention to in swine waste treatment processes.

\section{Conclusions}

This study showed a wide distribution of TRGs and SRGs in swine feedlots located in Shandong Province, China. RPP TRGs were predominant in swine wastes but tended to decrease after on-farm waste treatments and in waste-affected environmental matrices, while EFP TRGs and SRGs were recalcitrant to most treatment processes and persisted along the wastewater discharge and manure treatment paths. The MFB showed a "broad-spectrum" removal of all tested ARGs and thus could be a potential measure to

Table 2

Pearson's bivariate correlation analysis between the relative ARG abundances and bacterial orders.

\begin{tabular}{|c|c|c|c|c|c|c|c|c|c|}
\hline Order & Gram staining & Main oxygen demand & tetM & teto & tetw & tetC & tetG & sul1 & sul2 \\
\hline Rhizobiales & $\mathrm{G}^{-}$ & Aerobic & -0.490 & -0.371 & -0.421 & -0.119 & $0.857^{\mathrm{b}}$ & $0.828^{\mathrm{b}}$ & $0.804^{\mathrm{b}}$ \\
\hline Caulobacterales & $\mathrm{G}^{-}$ & Aerobic & -0.366 & -0.256 & -0.334 & 0.059 & $0.970^{\mathrm{a}}$ & $0.909^{\mathrm{a}}$ & $0.914^{\mathrm{a}}$ \\
\hline Burkholderiales & $\mathrm{G}^{-}$ & Aerobic & -0.251 & -0.122 & -0.237 & 0.170 & $0.991^{\mathrm{a}}$ & $0.983^{\mathrm{a}}$ & $0.984^{\mathrm{a}}$ \\
\hline Nitrosomonadales & $\mathrm{G}^{-}$ & Aerobic & -0.389 & -0.201 & -0.313 & -0.045 & $0.810^{\mathrm{b}}$ & $0.827^{\mathrm{b}}$ & $0.771^{\mathrm{b}}$ \\
\hline Hydrogenophilales & $\mathrm{G}^{-}$ & Anaerobic & $0.951^{\mathrm{a}}$ & $0.962^{\mathrm{a}}$ & $0.982^{\mathrm{a}}$ & $0.881^{\mathrm{a}}$ & -0.177 & -0.215 & -0.065 \\
\hline Alteromonadales & $\mathrm{G}^{-}$ & Aerobic & -0.300 & -0.096 & -0.247 & 0.035 & $0.826^{\mathrm{b}}$ & $0.932^{\mathrm{a}}$ & $0.863^{\mathrm{b}}$ \\
\hline Aeromonadales & $\mathrm{G}^{-}$ & Aerobic & $0.974^{\mathrm{a}}$ & $0.885^{\mathrm{a}}$ & $0.881^{\mathrm{a}}$ & $0.797^{\mathrm{b}}$ & -0.285 & -0.304 & -0.182 \\
\hline Coriobacteriales & $\mathrm{G}^{+}$ & Aerobic & $0.954^{\mathrm{a}}$ & $0.968^{\mathrm{a}}$ & $0.965^{\mathrm{a}}$ & $0.829^{\mathrm{b}}$ & -0.264 & -0.251 & -0.131 \\
\hline Erysipelotrichales & $\mathrm{G}^{-}$ & Aerobic & $0.972^{\mathrm{a}}$ & $0.917^{\mathrm{a}}$ & $0.892^{\mathrm{a}}$ & $0.807^{\mathrm{b}}$ & -0.276 & -0.267 & -0.156 \\
\hline Acholeplasmatales & No cell wall & Anaerobic & $0.984^{\mathrm{a}}$ & $0.911^{\mathrm{a}}$ & $0.902^{\mathrm{a}}$ & $0.833^{\mathrm{b}}$ & -0.255 & -0.271 & -0.143 \\
\hline Anaeroplasmatales & No cell wall & Anaerobic & $0.899^{\mathrm{a}}$ & $0.928^{\mathrm{a}}$ & $0.950^{\mathrm{a}}$ & $0.820^{\mathrm{a}}$ & -0.219 & -0.262 & -0.124 \\
\hline Spirochaetales & $\mathrm{G}^{-}$ & Variable & $0.770^{\mathrm{b}}$ & 0.748 & $0.756^{\mathrm{b}}$ & 0.723 & -0.220 & -0.239 & -0.102 \\
\hline Nitrospirales & $\mathrm{G}^{-}$ & Aerobic & $0.805^{\mathrm{b}}$ & $0.869^{b}$ & $0.856^{\mathrm{b}}$ & $0.800^{\mathrm{b}}$ & -0.030 & 0.014 & 0.132 \\
\hline Fusobacteriales & $\mathrm{G}^{-}$ & Anaerobic & $0.870^{\mathrm{b}}$ & $0.771^{\mathrm{b}}$ & 0.719 & $0.784^{\mathrm{b}}$ & -0.017 & -0.031 & 0.076 \\
\hline Bacteroidales & $\mathrm{G}^{-}$ & Anaerobic & $0.788^{\mathrm{b}}$ & $0.778^{\mathrm{b}}$ & $0.786^{\mathrm{b}}$ & 0.692 & -0.332 & -0.330 & -0.206 \\
\hline Flavobacteriales & $\mathrm{G}^{-}$ & Aerobic & -0.337 & -0.113 & -0.278 & -0.026 & $0.761^{\mathrm{b}}$ & $0.885^{\mathrm{a}}$ & $0.794^{b}$ \\
\hline Sphingobacteriales & $\mathrm{G}^{-}$ & Aerobic & -0.132 & 0.048 & -0.097 & 0.254 & $0.907^{\mathrm{a}}$ & $0.970^{\mathrm{a}}$ & $0.957^{\mathrm{a}}$ \\
\hline Fibrobacterales & $\mathrm{G}^{-}$ & Unknown & $0.950^{\mathrm{a}}$ & $0.837^{\mathrm{b}}$ & $0.831^{\mathrm{b}}$ & $0.765^{\mathrm{b}}$ & -0.296 & -0.319 & -0.200 \\
\hline Methanobacteriales & Undefined & Anaerobic & -0.069 & 0.075 & -0.043 & 0.333 & $0.911^{\mathrm{a}}$ & $0.932^{\mathrm{a}}$ & $0.957^{\mathrm{a}}$ \\
\hline
\end{tabular}

a Significance level $=0.01$.

b Significance level $=0.05$ 
control the ARGs in swine feedlots. However, the incompetence of most on-farm treatment processes in controlling ARGs alarms a necessary modification of waste management in swine feedlots.

\section{Acknowledgements}

This work was financially supported by the National Natural Science Foundation of China $(21590814,51678559,51525806)$ and the National Key Research and Development Program (2016YFD0501405). The authors gratefully thank Dr. James R. Bolton for polishing English.

\section{Appendix A. Supplementary data}

Supplementary data related to this article can be found at http:// dx.doi.org/10.1016/j.chemosphere.2016.10.013.

\section{References}

Aminov, R.I., Garrigues-Jeanjean, N., Mackie, R.I., 2001. Molecular ecology of tetracycline resistance: development and validation of primers for detection of tetracycline resistance genes encoding ribosomal protection proteins. Appl. Environ. Microbiol. 67 (1), 22-32.

Boyd, D.A., Peters, G.A., Ng, L.K., Mulvey, M.R., 2000. Partial characterization of a genomic island associated with the multidrug resistance region of Salmonella enterica Typhymurium DT104. FEMS Microbiol. Lett. 189 (2), 285-291.

Brooks, J.P., Adeli, A., McLaughlin, M.R., 2014. Microbial ecology, bacterial pathogens, and antibiotic resistant genes in swine manure wastewater as influenced by three swine management systems. Water Res. 57, 96-103.

Chen, J., Frederick, C.M.J., Sreevatsan, S., Morrison, M., Yu, Z., 2010. Occurrence and persistence of erythromycin resistance genes ( $\mathrm{erm}$ ) and tetracycline resistance Genes (tet) in waste treatment systems on swine farms. Microb. Ecol. 60, 479-486.

Cheng, W.X., Chen, H., Su, C., Yan, S.H., 2013. Abundance and persistence of antibiotic resistance genes in livestock farms: a comprehensive investigation in Eastern China. Environ. Int. 61, 1-7.

He, L.Y., Ying, G.G., Liu, Y.S., Su, H.C., Chen, J., Liu, S.S., Zhao, J.L., 2016. Discharge of swine wastes risks water quality and food safety: antibiotics and antibiotic resistance genes from swine sources to the receiving environments. Environ. Int. 92-93, 210-219.

Ji, X., Shen, Q., Liu, F., Ma, J., Xu, G., Wang, Y., Wu, M., 2012. Antibiotic resistance gene abundances associated with antibiotics and heavy metals in animal manures and agricultural soils adjacent to feedlots in Shanghai, China. J. Hazard. Mater. $235,178-185$

Jiang, X.Y., Sommer, S.G., Christensen, K.V., 2011. A review of the biogas industry in China. Energy Policy 39 (10), 6073-6081.

Johnson, T.A., Stedtfeld, R.D., Wang, Q., Cole, J.R., Hashsham, S.A., Looft, T., Zhu, Y., Tiedje, J.M., 2016. Clusters of antibiotic resistance genes enriched together stay together in swine agriculture. MBio 7 (2), e02214-e02215.

Koike, S., Krapac, I.G., Oliver, H.D., Yannarell, A.C., Chee-Sanford, J.C., Aminov, R.I., Mackie, R., 2007. Monitoring and source tracking of tetracycline resistance genes in lagoons and groundwater adjacent to swine production facilities over a 3-year period. Appl. Environ. Microbiol. 73 (15), 4813-4823.

Kristiansson, E., Fick, J., Janzon, A., Grabic, R., Rutgersson, C., Weijdegård, B., Söderström, H., Larsson, D.G., 2011. Pyrosequencing of antibiotic-contaminated river sediments reveals high levels of resistance and gene transfer elements. PLoS One 6 (2), e17038.

Li, J., Wang, T., Shao, B., Shen, J.Z., Wang, S.C., Wu, Y.N., 2012. Plasmid-mediated quinolone resistance genes and antibiotic residues in wastewater and soil adjacent to swine feedlots: potential transfer to agricultural lands. Environ.
Health Perspect. 120 (8), 1144-1149.

Liu, T., Kong, W., Chen, N., Zhu, J., Wang, J., He, X., Jin, Y., 2016. Bacterial characterization of Beijing drinking water by flow cytometry and MiSeq sequencing of the 16S rRNA gene. Ecol. Evol. 6 (4), 923-934.

Looft, T., Johnson, T.A., Allen, H.K., Bayles, D.O., Alt, D.P., Stedtfeld, R.D., Sul, W.J. Stedtfeld, T.M., Chai, B., Cole, J.R., Hashsham, S.A., Tiedje, J.M., Stanton, T.B., 2012. In-feed antibiotic effects on the swine intestinal microbiome. Proc. Natl. Acad. Sci. U. S. A. 109 (5), 1691-1696.

Mazel, D., 2006. Integrons: agents of bacterial evolution. Nat. Rev. Microbiol. 4 (8), 608-620.

Mckinney, C.W., Loftin, K.A., Meyer, M.T., Davis, J.G., Pruden, A., 2010. Tet and sul antibiotic resistance genes in livestock lagoons of various operation type, configuration, and antibiotic occurrence. Environ. Sci. Technol. 44 (16), 6102-6109.

Michelsen, C.F., Pedas, P., Glaring, M.A., Schjoerring, J.K., Stougaard, P., 2014. Bacterial diversity in Greenlandic soils as affected by potato cropping and inorganic versus organic fertilization. Polar Biol. 37 (1), 61-71.

Negreanu, Y., Pasternak, Z., Jurkevitch, E., Cytryn, E., 2012. Impact of treated wastewater irrigation on antibiotic resistance in agricultural soils. Environ. Sci. Technol. 46 (9), 4800-4808.

Peak, N., Knapp, C.W., Yang, R.K., Hanfelt, M.M., Smith, M.S., Aga, D.S., Graham, D.W. 2007. Abundance of six tetracycline resistance genes in wastewater lagoons at cattle feedlots with different antibiotic use strategies. Environ. Microbiol. 9 (1), 143-151.

Pei, R., Cha, J., Carlson, K.H., Pruden, A., 2007. Response of antibiotic resistance genes (ARG) to biologial treatment in dairy lagoon water. Environ. Sci. Technol. 41, $5108-5113$.

Peng, S., Wang, Y.M., Zhou, B.B., Lin, X.G., 2015. Long-term application of fresh and composted manure increase tetracycline resistance in the arable soil of Eastern China. Sci. Total Environ. 506-507, 279-286.

Pruden, A., Pei, R., Storteboom, H., Carlson, K.H., 2006. Antibiotic resistance genes as emerging contaminants: studies in northern Colorado. Environ. Sci. Technol. 40 (23), 7445-7450.

Roberts, M.C., 2012. Acquired tetracycline resistance genes. In: Dougherty, T.J. Pucci, M.J. (Eds.), Antibiotic Discovery and Development. Springer US, New York, pp. 543-568.

Saini, R., Halverson, L.J., Lorimor, J.C., 2003. Rainfall timing and frequency influence on leaching of Escherichia coli RS2G through soil following manure application. J. Environ. Qual. 32 (5), 1865-1872.

Sköld, O., 2000. Sulfonamide resistance: mechanisms and trends. Drug Resist. Update 3 (3), 155-160.

Smalla, K., Heuer, H., Gotz, A., Niemeyer, D., Krogerrecklenfort, E., Tietze, E., 2000 Exogenous isolation of antibiotic resistance plasmids from piggery manure slurries reveals a high prevalence and diversity of IncQ-like plasmids. Appl. Environ. Microbiol. 66 (11), 4854-4862.

Thomas, C.M., Nielsen, K.M., 2005. Mechanisms of, and barriers to, horizontal gene transfer between bacteria. Nat. Rev. Microbiol. 3 (9), 711-721.

Wang, J., Ben, W.W., Zhang, Y., Yang, M., Qiang, Z.M., 2015. Effects of thermophilic composting on oxytetracycline, sulfamethazine, and corresponding resistance genes in swine manure. Environ. Sci. Process. Impacts 17, 1654-1660.

Wang, J., Ben, W.W., Yang, M., Zhang, Y., Qiang, Z.M., 2016. Dissemination of veterinary antibiotics and corresponding resistance genes from a concentrated swine feedlot along the waste treatment paths. Environ. Int. 92-93, 317-323.

Wang, L., Guo, Z.Y., 2009. The biological fermentation bed raises pigs technical the application present situation. Livest. Poult. Ind. 3, 8-10.

Wu, N., Qiao, M., Zhang, B., Cheng, W.D., Zhu, Y.G., 2010. Abundance and diversity of tetracycline resistance genes in soils adjacent to representative swine feedlots in China. Environ. Sci. Technol. 44 (18), 6933-6939.

Zhang, Q.Q., Ying, G.G., Pan, C.G., Liu, Y.S., Zhao, J.L., 2015. A comprehensive evaluation of antibiotics emission and fate in the river basins of China: source analysis, multimedia modelling, and linkage to bacterial resistance. Environ. Sci. Technol. 49 (11), 6772-6782.

Zhu, Y.G., Johnson, T.A., Su, J.Q., Qiao, M., Guo, G.X., Stedtfeld, R.D., Hashsham, S.A. Tiedje, J.M., 2013. Diverse and abundant antibiotic resistance genes in Chinese swine farms. Proc. Natl. Acad. Sci. U. S. A. 110 (9), 3435-3440. 